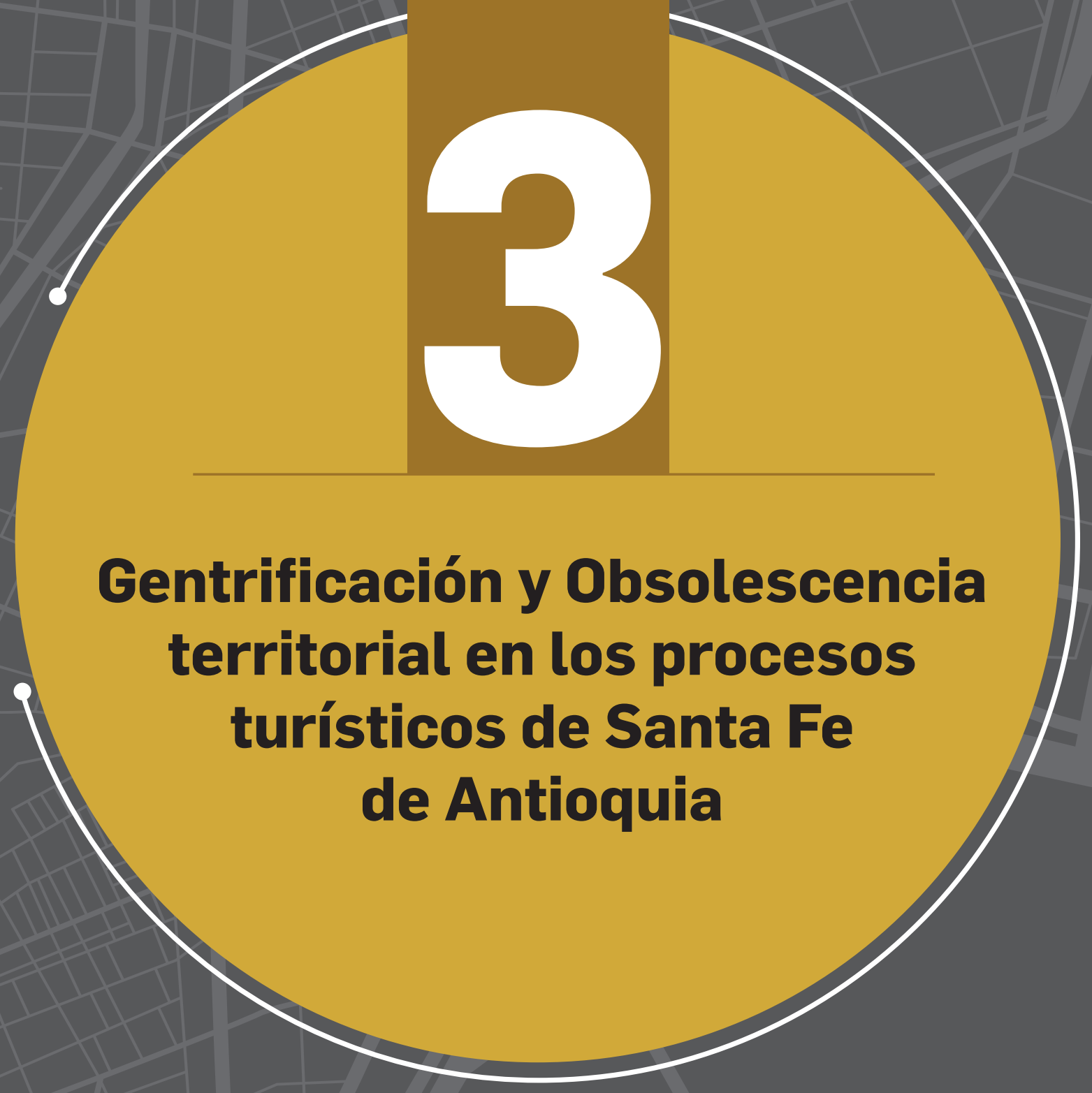

Elkin Argiro Muñoz Arroyave 



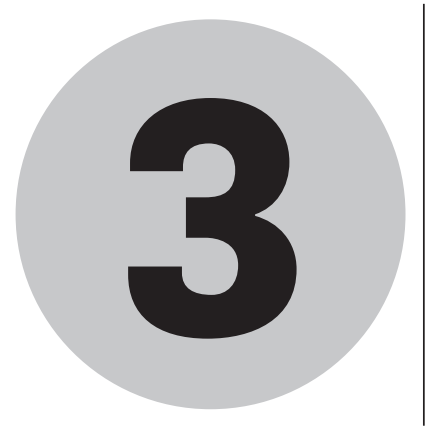

\section{Gentrificación y Obsolescencia territorial en los procesos turísticos de Santa Fe de Antioquia}

Elkin Argiro Muñoz Arroyave*

\section{Resumen}

Los procesos urbanos en la actualidad son complejos, debidoalaltonúmero deactores, relaciones y fenómenos involucrados. Dos de ellos son la gentrificación y la obsolescencia territorial, los cuales favorecen ciertos intereses en los territorios en perjuicio de otros. En esta medida, el objetivo de este capítulo es reflexionar teóricamente alrededor del concepto, manifestación, consecuencias e incidencias del turismo entre la gentrificación y la obsolescencia territorial. Se empleó una metodología de revisión de literatura, el análisis del investigador, así como la aplicación a un caso real, con la finalidad de observar los fenómenos de manera empírica. Se concluye que el turismo es capaz de manifestar gentrificación y obsolescencia territorial al

Palabras clave: gentrificación, obsolescencia, turismo y territorio. mismo tiempo en un territorio, ocasionando conflictos y tensiones entre actores sociales. Sin embargo, a partir del discurso de desarrollo que acompaña al turismo, en pocas ocasiones se va en su contra, a pesar de incentivar fenómenos urbanos como estos.

* Economista, magíster en Desarrollo Regional y Planificación del Territorio, candidato a doctor en Estudios Territoriales. Docente investigador del Tecnológico de Antioquia Institución Universitaria. Correo: elkin.munoz@tdea.edu.co 


\section{Introducción}

l turismo es una práctica social que se deriva del viaje y la satisfacción del deseo de conocer nuevos espacios y culturas, aunque, al mismo tiempo, va creando ese deseo o necesidad. Históricamente se han identificado diversos antecedentes para la actividad turística actual, algunos de ellos son los lugares de peregrinaciones, el Grand Tour, entre otros (Vera et al., 2013). Sin embargo, el turismo actual y esas peregrinaciones no son realmente cercanos, debido a que sus finalidades eran de corte religioso 0 político, mientras que el turismo actual tiene otras muy diferentes, las cuales hacen difícil la semejanza con aquellos, más allá del hecho del viaje.

El fenómeno turístico actual tiene una doble finalidad, según el actor social desde el cual se analice: para los actores empresariales, gubernamentales, financieros e incluso residentes del destino, la finalidad es económica; mientras que para los turistas y, en alguna medida, para los residentes, la finalidad es social. En sí, la importancia económica del turismo radica en la movilización de recursos financieros ${ }^{1}$; así, los diferentes actores que se benefician por esta dinamización ven en el turismo un fin altamente económico.

Esta importancia económica del turismo le da la oportunidad de transformar aquellos territorios que son visitados, pero tales transformaciones parten de la imagen que se desea transmitir al turista para que visite el destino. Al funcionar de esta forma, se observa un comportamiento dicotómico, en donde aquello que se acopla a la imagen vendida, va a ser resaltado y promocionado, mientras aquello

1 A través del pago por los servicios que utiliza un turista en el destino como las agencias de viaje, servicios de transporte, guías turísticos, alimentación, hospedaje, compra de souvenirs, acceso a museos, entre otros. 
que no se acople, tenderá a ser ocultado, segregado y fragmentado del resto del territorio. De esta manera, los actores turísticos se alinean con un discurso de desarrollo, en el que se muestran con capacidad de intervenir en el territorio y como una solución a las problemáticas locales. Así, aquel que se pronuncie en contra del turismo, está yendo en contra del progreso y desarrollo, algo que es impensado en la sociedad actual.

Este capítulo tiene la finalidad de reflexionar sobre cómo el turismo transforma los territorios y, particularmente, permite que los fenómenos de obsolescencia y gentrificación se presenten en un territorio simultáneamente. A lo largo del capítulo se discutirá la relevancia de esa sincronía de fenómenos que en un momento parecieran ser contrarios o que uno es un paso inicial para el otro. De ahí, la importancia que tiene el turismo, ya que hace las veces de mediador entre ambos conceptos en el territorio.

En esta medida, la metodología aplicada es cualitativa, basada en la revisión documental y la reflexión teórico-práctica del autor. En la revisión documental se utilizaron categorías de análisis como la gentrificación, la obsolescencia y el deterioro para seleccionar los documentos analizados y la manera en que teóricamente, y en general, trataban el tema en el turismo. En el aspecto empírico, es decir, para la reflexión práctica, se utilizó como principal técnica de investigación los recorridos territoriales. Esta técnica consiste en combinar el reconocimiento directo de los espacios a través de caminar por las calles, con diálogos cortos con la comunidad y una observación sistematizada de lo identificado. En este caso, se aplicó a Santa Fe de Antioquia durante tres visitas que permitieron recorrer sus barrios principales, lugares turísticos y tres veredas de la zona rural. La visita de los barrios fue comentada y realizada en compañía de un funcionario de la Alcaldía municipal y miembro del Centro de Historia municipal, con lo que se pudo conocer aspectos puntuales del municipio. 
Así, el capítulo hace una reflexión teórica sobre estos dos fenómenos y su relación con el territorio y hace una aplicación de esta interpretación al caso específico de Santa Fe de Antioquia, esta doble finalidad, a su vez, representa las dos secciones en las que está dividido el escrito.

\section{Gentrificación y obsolescencia territorial a través del turismo}

Antes de profundizar en los dos conceptos centrales de este capítulo, es conveniente hacer un pequeño análisis de aquello que es transformado por esos fenómenos: el territorio. Para ello parto de la conceptualización dada por Raffestin (2011):

El territorio se apoya en el espacio, pero no es el espacio sino una producción a partir de él. Es la producción para todas las relaciones de los recursos y se inscribe en un campo de poder. Producir una representación del espacio es ya una apropiación, un dominio, un control, inclusive si permanece dentro de los límites de un conocimiento. Cualquier proyecto en el espacio que se expresa como una representación revela la imagen deseada del territorio como lugar de relaciones (p. 102).

El territorio, según esto, implica relaciones de poder entre actores, y entre estos y el espacio. El resultado de estas relaciones es un proceso de apropiación que se daría a partir de las representaciones que se hacen esos actores del espacio. Se van manifestando representaciones del espacio en medio de las relaciones de poder que se dan; aquí es fundamental el papel de Foucault (1984) para dar una explicación teórica de este proceso. Frente al poder, este autor menciona que cuando se analiza, lo más importante es determinar sus mecanismos y relaciones; además, para él, el poder no es una propiedad, sino una estrategia que no se posee, sino que se ejerce. Es decir, esas relaciones de poder dentro de un espacio pueden entonces 
lograr modificaciones en las acciones de otros actores que van a llevar a la producción del territorio.

Los fenómenos que se plantean en este capítulo están inmersos en las formas actuales de producción territorial que desde Haesbaert están inmersas en un proceso de desterritorialización y reterritorialización. Esto implica que "el territorio debe ser concebido como producto del movimiento combinado de desterritorialización y de reterritorialización, es decir, de las relaciones de poder construidas en y con el espacio" (Haesbaert, 2013, p. 26). Asimismo, la relación entre gentrificación y obsolescencia territorial, mediada por el turismo es una suerte de multiterritorialidad, la cual "es la posibilidad de tener la experiencia simultánea y/o sucesiva de diferentes territorios, reconstruyendo constantemente el propio" (Haesbaert, 2013, p. 35). Esto se profundizará a continuación, en la presentación de los dos fenómenos planteados.

En los últimos años, los estudios que se dedican a trabajar el tema de la gentrificación han comenzado a observar este concepto en relación con el turismo (Hiernaux y González, 2014a; Hiernaux y González, 2014b; Kesar, Dezeljin, y Bienenfeld, 2015; Ossa y Rippes, 2014). Así, la gentrificación ha sido entendida por diferentes autores tradicionales (Smith, 1996) como el proceso de reemplazo de un grupo social por otro que generalmente presenta un poder adquisitivo mayor que el grupo inicial. Esto implica un cambio arquitectónico en el espacio que recibe a este nuevo grupo, atendiendo a sus necesidades estéticas y habitacionales.

En la literatura se ha generalizado tres tipos de espacios que son más susceptibles de gentrificar. Los primeros son espacios que se caracterizan por haber sido foco de desarrollo industrial, esto quiere decir que en el nuevo contexto global y de producción flexible son expulsados de las ciudades; los segundos son espacios de zonas 
céntricas de las ciudades dedicados o habitados por poblaciones de bajos recursos, tradicionales y trabajadoras; finalmente, espacios periféricos, en donde se están localizando personas interesadas por unas condiciones diferenciadas a las de la ciudad.

En el caso específico del turismo, es posible entender que la gentrificación es un proceso que se puede materializar en cualquier tipo de espacio con potencial turístico. Así, uno de los casos más estudiados es el de los centros históricos (Hiernaux y González, $2014 b)$, en donde las construcciones y adecuaciones para la oferta turística son fundamentales y expulsan a poblaciones tradicionales. Un aspecto que diferencia la gentrificación turística de otras es que la finalidad de las construcciones realizadas no es la de habitar, sino su uso temporal durante los momentos de ocio.

Esto tiene implicaciones sobre la producción territorial, ya que en este caso el espacio va a tener un carácter temporal diferente al del resto del territorio y a las temporalidades previas; las relaciones sociales no van a ser estables en el tiempo, sino que van a depender del flujo turístico; adicionalmente, cada turista traerá sus propias prácticas, territorialidades y territorializaciones, por lo que la apropiación de ese espacio será diferenciado durante los tiempos de visita en las que predominan esas prácticas y discursos temporales. Todos estos elementos contrastan con la producción realizada por los actores que han sido expulsados y que tendía a ser más continua en el tiempo y de manera colectiva.

Estas construcciones gentrificadoras del turismo van a estar enmarcadas en la imagen y el imaginario que se produzca sobre el destino turístico. De esta forma, el mercadeo del destino va a definir el tipo de construcciones que se realizarán, qué espacios son los adecuados para que estas construcciones se vean rodeadas de otras que cumplan con esa imagen o para que se realicen las intervenciones 
necesarias para ocultar aquello que no corresponda. Cada una de estas decisiones va a tener una implicación sobre la producción territorial del destino, que se va a ver transformada por estas características del turismo.

La gentrificación no solamente se refiere al desplazamiento directo de la población, también hay accionese intervenciones gentrificadoras. Es decir, es posible que en el momento de la intervención no se desplace inmediatamente a la población tradicional, pero sí que las nuevas prácticas e intervenciones puedan lograr que en momentos posteriores se expulse a la población (Cócola, 2015). Incluso no de una manera beligerante, se pueden utilizar elementos sutiles, hasta ir mostrando que esa población es obsoleta y desplazarlos o que ellos sientan que no encajan en ese contexto y también se desplacen. Así, la exclusión de los residentes también puede ser

provoked by visitors, and so it illustrates how tourism can be interpreted as a gentrifying process. [...] The visitor is regarded as an affluent user that overlaps with other daily dynamics of the city and, as a result, the gentrification of lower income communities will be more intense in areas that have been transformed into spaces for tourism consumption (Cócola, 2015, pp. 2-3)².

Estos elementos hacen parte de las nuevas formas de gentrificación que se presentan en la sociedad actual, bien sea porque no se dan en zonas tradicionalmente urbanas, ya que ahora tienen presencia en zonas rurales y rururbanas (Nates, 2008), o como en este caso que se habla de una gentrificación comercial:

2 "provocado por los visitantes, por lo que ilustra cómo el turismo puede interpretarse como un proceso de gentrificación. [...] Se considera al visitante como un usuario acomodado que se solapa con otras dinámicas cotidianas de la ciudad $\mathrm{y}$, como resultado, la gentrificación de las comunidades de menores ingresos será más intensa en áreas que se han transformado en espacios de consumo turístico" (Traducción propia). 
It has been stated that commercial gentrification is part of a broader process of symbolic gentrification (Bolzoni, 2014; Janoschka, Sequera, \& Salinas, 2014; Rousseau, 2009), a revitalisation process in which the agents of change are not new middle class residents, but new spaces and services aimed at attracting them (Cócola, 2015, p. 33).

En el caso específico del turismo se puede ver que los "residents are moving out more because of the transformation of uses and users in their neighbourhoods and not only because of the dynamics of the housing market" (Cócola, 2015, p. 3) ${ }^{4}$. Esto hace referencia a una gentrificación que no se presenta al mismo tiempo que la intervención. Es una gentrificación de mediano y largo plazo, donde el desplazamiento de la población tradicional se logra a partir de las acciones y prácticas de los visitantes. Los actores económicos y del sector público se enfocan en la atracción de esos actores flotantes, dejando a los residentes y sus problemas ante los nuevos actores relegados, ya que se supone que es un mal menor que se compensa con el mayor crecimiento económico propiciado por los turistas.

Así, la gentrificación comercial tiene dos efectos complementarios, el desplazamiento del comercio local y la atracción de un consumo diferente:

While commercial displacement destroys local businesses and changes the nature of the consumption facilities in an area, the

3 "Se ha planteado que la gentrificación comercial es parte de un proceso más amplio de gentrificación simbólica (Bolzoni, 2014; Janoschka, Sequera y Salinas, 2014; Rousseau, 2009), un proceso de revitalización en el que los agentes del cambio no son los nuevos residentes de clase media, sino nuevos espacios y servicios orientados a atraerlos" (Traducción propia).

4 “los residentes se están mudando más por la transformación de usos y usuarios en sus barrios y no solo por la dinámica del mercado de la vivienda" (Traducción propia). 
important point is that it leads to a complete mutation in how the neighbourhood is used and by whom, including loss of services which low income residents rely on for their everyday life; privatisation of public space or affordability problems (Cócola, 2015, p. 4)5.

Por otra parte, la obsolescencia territorial la vamos a entender como aquel proceso adelantado, desde uno o varios actores sociales, sobre un lugar o práctica, para comenzarlos a percibir, representar y actuar sobre ellos como lugares o prácticas deteriorados, en desuso 0 inadecuados para el contexto en el que se desarrollan. Es de resaltar que la obsolescencia territorial siempre está asociada a un punto de vista de uno o varios actores sociales, ya que es muy probable que para personas que desarrollan parte de su vida dentro de ese lugar 0 son partícipes de la práctica en cuestión, no sean obsoletos.

El papel que juegan los actores sociales en la definición de la obsolescencia territorial es una muestra de las relaciones de poder que están inmersas dentro de este proceso. Dependiendo del juego de intereses, se puede lograr o no definir un lugar o práctica como obsoleta. El uso cotidiano de algunos lugares y la permanencia e innovación de las prácticas sociales son algunos aspectos claves para que el territorio responda a las posiciones que determinan los procesos de obsolescencia. En las geometrías del poder (Massey, 1993) de los territorios contemporáneos, los poderes económicos y políticos suelen ser los que moldean las decisiones territoriales, por lo que deciden cuáles son los espacios obsoletos y cuándo intervenir sobre ellos.

5 "Si bien el desplazamiento comercial destruye los negocios locales y cambia la naturaleza de las instalaciones de consumo en un área, el punto importante es que conduce a una mutación completa en cómo se usa el vecindario y por quién, incluida la pérdida de servicios de los que dependen los residentes de bajos ingresos para su vida diaria; la privatización del espacio público o los problemas de asequibilidad" (Traducción propia). 
La obsolescencia generalmente se asocia a las condiciones físicas del espacio, tales como: condiciones estéticas, arquitectónicas, tipos de materiales, condiciones urbanísticas, provisión de servicios públicos, entre otros. Cualquiera de estos elementos que se aleje del promedio o imagen mental que se tiene desde la modernidad (de cómo deberían ser) va a provocar que ese espacio vaya a ser considerado obsolescente. Pero la obsolescencia territorial no solamente se clasifica a partir de aspectos físicos, también desde las prácticas sociales, culturales y económicas. Por ejemplo, el envío de cartas y postales, en la época actual, se ve como una práctica obsoleta desde los actores que están más relacionados con las Tecnologías de la Información y la Comunicación (TIC).

De esta forma, dentro de un territorio se puede presentar la obsolescencia tanto por el deterioro físico del espacio como por no encajar en la imagen urbana o rural moderna, aunque esta última también se da por considerar que ciertas prácticas del territorio son obsoletas. Ambos tipos de obsolescencia se pueden presentar al mismo tiempo, no necesariamente se presentan por separado; pero siempre corresponde a una declaración o clasificación desde el punto de vista de uno o varios actores sociales, pocas veces hay unanimidad en la determinación de obsolescencia.

Cuando hablamos del turismo y su relación con la obsolescencia territorial debemos retomar la producción de lugares y territorios desde el turismo, donde la imagen y el imaginario son aspectos fundamentales. La imagen del destino turístico es la que puede crear un imaginario en el turista para que visite este lugar; de ahí que deba ser atractiva, que refleje la belleza del lugar o de la práctica que se quiera promocionar, que sea una imagen homogénea en el espacio y, aún más importante, que el lugar efectivamente se acople a esa imagen, es decir, que esa proyección o imaginario que se le crea al turista efectivamente se cumpla en el destino turístico. 
El sector turístico buscará que el espacio se comporte de acuerdo con la imagen que se ha creado del destino; por tanto, aquel espacio que no se adecúe a esa imagen es considerado por estos actores como obsolescente u obsoleto. A esta clasificación y el proceso de ocultación de esos espacios que el turismo considera como obsoletos, es a lo que le denomino obsolescencia turística. Generalmente, se refiere a los espacios residenciales locales, que, en la mayoría de los tipos de turismo, a excepción del turismo etnográfico, tienden a ser ocultados o separados física o socialmente del resto del destino turístico. Un espacio con obsolescencia turística tenderá a ser intervenido para que refleje la imagen con la que se quiere posicionar a este.

De otro lado, las prácticas sociales, desde el turismo, no se identifican como obsolescentes ${ }^{6}$, ya que mientras menos modernas y estandarizadas sean en la sociedad de destino, van a ser más atractivas para el turista; es decir, el turismo incluso promueve prácticas que desde otros puntos de vista puedan parecer obsoletas. Esto se debe a la necesidad de lo exótico y diferente que busca el turista. Sin embargo, desde los residentes sí es posible que el turismo provoque una obsolescencia a partir de las prácticas sociales.

Cuando se comienza a fortalecer el turismo en un destino y los turistas se apropian de ciertos lugares, a partir de diferentes prácticas sociales, propias del esparcimiento ${ }^{7}$, es probable que la población residente sienta que esas prácticas no se adecúan a sus ritmos, momentos y prácticas locales. Al identificar que en esos lugares se desarrollan prácticas que no corresponden al contexto territorial producido por los residentes, estos comienzan a alejarse de aquellos lugares y a considerarlos obsolescentes por el tipo de prácticas y no por las características físicas de los mismos. A este tipo de obsolescencia asociada al turismo, se le va a denominar

6 A no ser que sean unas prácticas que perjudiquen al turista.

7 Sonidos muy altos, prostitución, fiestas hasta altas horas de la noche, peleas en el espacio público, etc. 
turismo obsolescente, haciendo referencia a las prácticas turísticas que desde los residentes son rechazadas.

Ahora bien, cuando se declara un territorio (por las características físicas o las prácticas sociales) como obsolescente, se convierte en una necesidad de intervención para mejorar esa situación. Por tanto, al declarar un espacio como obsolescente por parte del sector turístico, se tenderá a ocultarlo para que no genere en el turista la sensación de incumplimiento con el imaginario creado. Esto se puede hacer simplemente a partir de señalizaciones, definición de mapas turísticos, iluminación de los espacios, entre otros mecanismos, pero principalmente la intervención sería arquitectónica, construyendo nuevas edificaciones que sí respondan a esa imagen. El aumento de los precios de los suelos, debido a su cercanía con atractivos turísticos, es una de las maneras de impulsar a los propietarios de esos espacios declarados como obsolescentes para que vendan y así poder adecuarlos.

El turismo y la producción de imágenes sobre los destinos inducen a la obsolescencia de algunos sectores del territorio; para resolverlo, se recurre a la construcción de lugares de oferta turística que generan gentrificación. Igualmente, cuando el destino comienza a identificar prácticas obsoletas de parte de los turistas, tiende a desplazar o autoexcluir esos espacios, lo que sería un reflejo de una gentrificación comercial (Cócola, 2015). Así, se puede afirmar que estos fenómenos se producen simultáneamente con el turismo. Esa conexión de los dos fenómenos con el turismo provoca una nueva producción territorial, de ahí que podamos afirmar la influencia del turismo en la transformación del territorio, a través de la gentrificación y la obsolescencia ${ }^{8}$.

8 Esto se puede asemejar a la multiterritorialidad mencionada por Haesbaert (2013), aunque aquí el esfuerzo teórico se centró en identificar específicamente los fenómenos que están transformando y construyendo un nuevo territorio. 
Ese nuevo territorio que se produce por el turismo es lo que denomino territorio de postal (Muñoz, 2017), el cual es un territorio producido a partir del turismo, que se caracteriza por la exaltación, la apertura y la promoción de ciertos espacios (o prácticas) que responden a una imagen creada sobre el destino. Esta imagen se trata de fortalecer cada vez más, probablemente a partir de un proceso de gentrificación, pero también por la ocultación, el deterioro, la separación y la obsolescencia de aquellos espacios (o prácticas) que no corresponden a esa imagen del destino. Se podría resumir, por tanto, la relación entre estos conceptos en la Figura 1.

Figura 1. Expresiones de la gentrificación y la obsolescencia territorial en el proceso turístico.

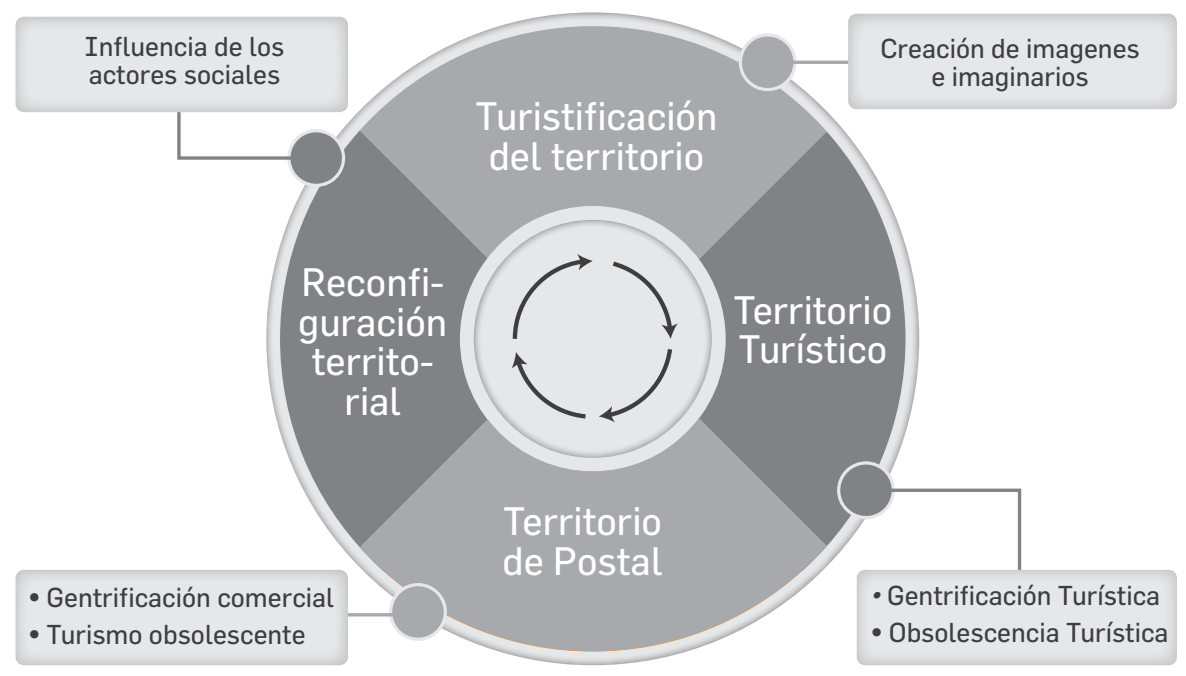

Fuente: Elaboración propia.

El proceso inicia con una turistificación del territorio, lo que normalmente se ha llamado el aprovechamiento de los atractivos turísticos de este. Para ello se crean imágenes que redundarán en la creación de imaginarios dentro y fuera del territorio de destino. 
Una vez se inicia este proceso, se puede hablar de un territorio turístico, que intentaría ser configurado a partir de los intereses del sistema turístico. Para ello interviene a través de un doble proceso: gentrificación turística, es decir, el desplazamiento efectivo de población tradicional por la construcción de nuevos escenarios y equipamientos para el turismo; consolidación de una obsolescencia turística, es decir, clasificar los demás sectores del destino que no se puedan acoplar a la imagen proyectada como si fueran deteriorados o fuera de ese contexto.

Conjugados estos elementos se crea lo que hemos denominado un territorio de postal, caracterizado por la fragmentación del territorio en lugares que exponen la imagen turística fomentada y otros que no lo hacen, y que tienden a ser excluidos. Dentro de este territorio de postal se crean dos fenómenos complementarios:

1. La gentrificación comercial, entendida como una gentrificación a mediano y largo plazo, la cual induce poco a poco al desplazamiento de los residentes, a partir de comportamientos de todos los visitantes, no sólo los turistas.

2. El turismo obsolescente que desde la perspectiva del residente observa espacios y prácticas deterioradas a partir de la presencia de los turistas.

Pero el proceso sería unilateral, si no se tuvieran en cuenta las reacciones que tienen los actores locales frente a las acciones sobre su territorio. De esta manera, el ciclo se complementa con la reconfiguración territorial que es producto de la influencia de los actores y sus interrelaciones. En otras palabras, esto no quiere decir que las reacciones de los locales vayan a cambiar todo el proceso, pero en la interacción de dinámicas locales y globales se obtendrán nuevos resultados que reconfigurarán el territorio; bien sea a favor de los intereses de unos u otros. 
Esquemáticamente sólo se realizó una expresión teóricoconceptual de este proceso, pero en realidad se puede identificar que la reconfiguración territorial se presenta en cada paso, que las posturas de los actores están en cada momento, hasta limitar el surgimiento de un territorio de postal; todo depende de las condiciones de cada destino turístico, los intereses que estén en juego, los actores que adelanten los procesos de turistificación, entre otras variables. Sin embargo, es una guía inicial para el análisis de este tipo de relaciones. Es probable que en general, los destinos turísticos presenten este tipo de comportamiento y de producción territorial, pero en este caso se analiza para el municipio de Santa Fe de Antioquia en Colombia.

\section{Caracterización de la gentrificación y la obsolescencia en Santa Fe de Antioquia}

Santa Fe de Antioquia es un municipio ubicado en la subregión occidente del departamento de Antioquia, cuenta con aproximadamente 25.000 habitantes (Gobernación de Antioquia y Departamento Administrativo de Planeación, 2017), que en su mayoría se han dedicado a las actividades agropecuarias, sobresaliendo en la producción de café, ganadería y cítricos. Es de destacar que Santa Fe de Antioquia históricamente representa la cuna de la cultura paisa, debido a que fue el lugar donde se asentaron inicialmente los españoles y fue la primera capital de Antioquia, pero pierde este papel con Medellín, por su posicionamiento económico poco después de la independencia nacional.

Esta importancia histórica se refleja en su centro histórico que hoy en día se convierte en uno de sus principales atractivos turísticos. En las décadas de los años 70 y 80 del siglo XX se inicia la construcción de una infraestructura turística de hoteles y hosterías en el centro histórico. Cada una de estas construcciones contaba con piscina y una arquitectura para el descanso de veraneo, dado el clima con el que 
cuenta el municipio $\left(27^{\circ} \mathrm{C}\right.$ en promedio). Estos aspectos, y su cercanía con Medellín, convierten a Santa Fe de Antioquia en un destino de veraneo para este centro urbano. En el año 2006 se abre el túnel de occidente que acerca aún más a ambos municipios, el tiempo de viaje actual está alrededor de una hora, y desde ese momento se dispara el flujo de turistas y la construcción de hoteles, hosterías, segundas residencias, condominios y fincas.

En la Figura 2 es posible observar los puntos en dónde se localizan piscinas en el municipio. En azul se designan las piscinas que existían para el año 2010, en verde las que se construyen adicionalmente en 2019. Es de resaltar la cantidad de este artefacto de la modernidad y muestra del ocio global en el municipio. Para el año 2010 se lograron observar un total de 234, el número aumenta en 2019 a 359, lo que significa que en 9 años se construyen 125 piscinas, es decir, el $35 \%$ del total. Lo que muestra este pequeño ejercicio es que el turismo de veraneo se ha posicionado en Santa Fe, el espacio se sigue apropiando para producir este tipo de lugares de veraneo. 
Figura 2. Localización de piscinas en la zona urbana, 2010-2019.

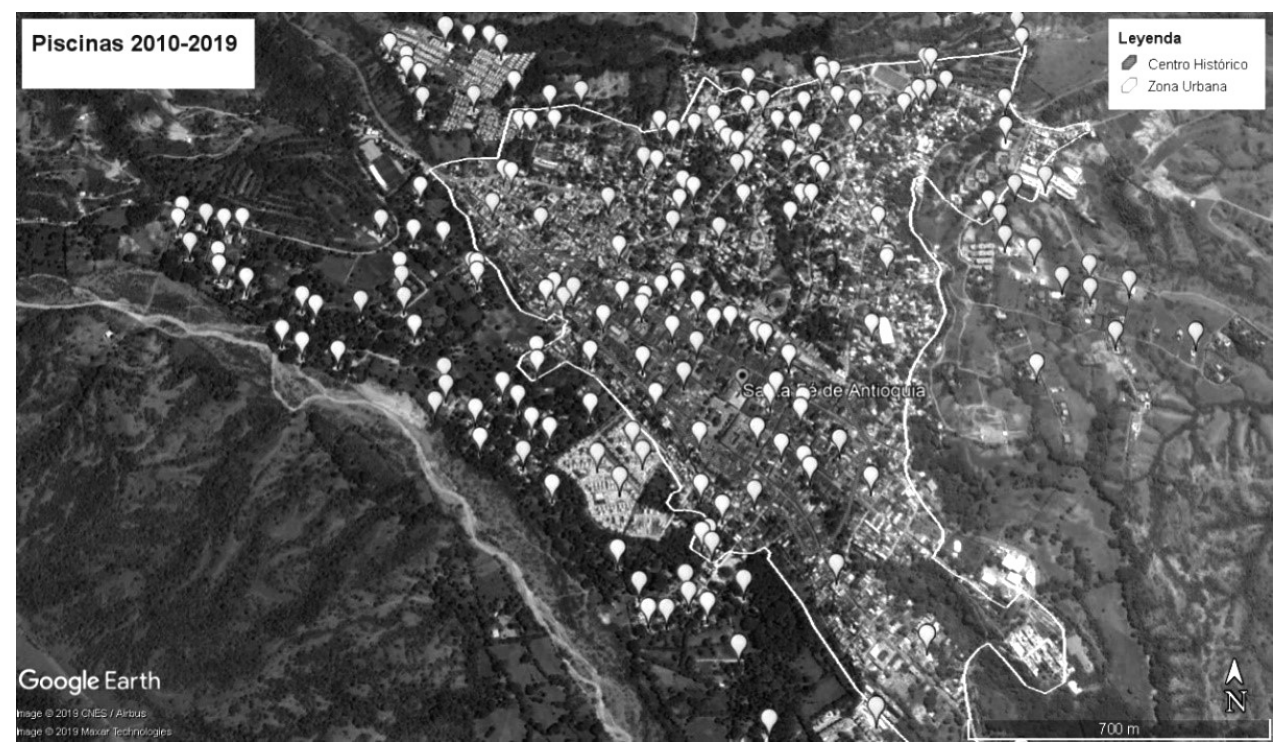

Fuente: Elaboración propia con base en Google (2019).

Se pueden concluir dos elementos de la localización de las piscinas. En primer lugar, la mayoría de ellas se encuentran en el Centro Histórico y en la zona del Llano de Bolívar (hacia la esquina superior derecha de la zona urbana). Esto se debe a que en el Centro se localizan la mayoría de los hoteles y restaurantes para el servicio del turista. Mientras en el Llano de Bolívar se han venido creando nuevas instalaciones para los turistas y los locales. En segundo lugar, es de resaltar que las nuevas construcciones se dan principalmente en las afueras del Centro Histórico y de la Zona Urbana; esto se puede explicar por los altos costos del suelo en el Centro y porque se quiere mostrar una imagen de finca campestre y, por ello, es necesario que estas construcciones sean alejadas de las zonas más urbanizadas.

De otro lado, las condiciones socioeconómicas del municipio son de cierta forma dispares, ya que se da una mejora en la dinámica económica, 
pero no en la calidad de vida. Según la Cámara de Comercio de Medellín (2016), el municipio contaba con un total de 744 empresas para el año 2015 , representando un crecimiento del $98,9 \%$ respecto al año 2011 , lo que económicamente es realmente llamativo. No obstante, si miramos las condiciones sociales según el nivel del Sisben, en la zona urbana casi un $60 \%$ de la población se encuentra en condiciones de pobreza, mientras en la zona rural poco más del 80\% (Gobernación de Antioquia y Departamento Administrativo de Planeación, 2017).

Esto quiere decir que el desempeño económico no ha sido capaz de satisfacer las necesidades de la población local. Parte de esto se puede explicar por el hecho de que la estructura empresarial del municipio se concentra en el comercio al por menor (52\%) y en alojamientos y servicios de comida (20,2\%) (Cámara de Comercio de Medellín, 2015). Estas actividades se relacionan directamente con el turismo, ligando su éxito o fracaso comercial al flujo de turistas. La dependencia de esta actividad hace que sus habitantes, la mayoría del tiempo, no encuentren unas fuentes estables de ingresos y esto explicaría sus condiciones sociales.

A estas condiciones socioeconómicas hay que sumar el hecho de que las nuevas construcciones comenzaron a competir fuertemente por el uso del suelo, lo que incrementó su precio y afectaron las ganancias de algunos campesinos, obligándolos a vender sus tierras y a cambiar las actividades a las que se dedicaban (Instituto de Estudios Regionales, 2007; Universidad Nacional de Colombia, 2006). Espacialmente se reconfigura el municipio, a lo largo de la vía MedellínUrabá donde comienzan a ubicarse las parcelaciones y condominios, lugares que anteriormente eran dedicados a la producción de cítricos y el famoso tamarindo de la región (Ver Figura 3).

Ahora bien, el turismo de sol es el que más se ha fortalecido en el municipio, aparte de competir con los usos del suelo tradicional, 
también lo está haciendo con el turismo cultural y patrimonial. En el centro histórico también se están concentrando la mayoría de las discotecas, bares y licorerías, que atraen a turistas que no están interesados en el patrimonio histórico, lo que ha comenzado a perjudicar la sostenibilidad de este. Se han llevado nuevas dinámicas que afectan el comportamiento social, como la prostitución, que se acrecienta al no tener demasiadas alternativas productivas. Estas dinámicas han sido afianzadas por la política de conectividad nacional que llevó a la construcción del túnel de occidente y, como se mencionó anteriormente, es uno de los detonantes de las actividades turísticas y todo su sistema de relaciones.

Figura 3. Localización de proyectos de parcelaciones y vías en Santa Fe de Antioquia, 2009-2012.

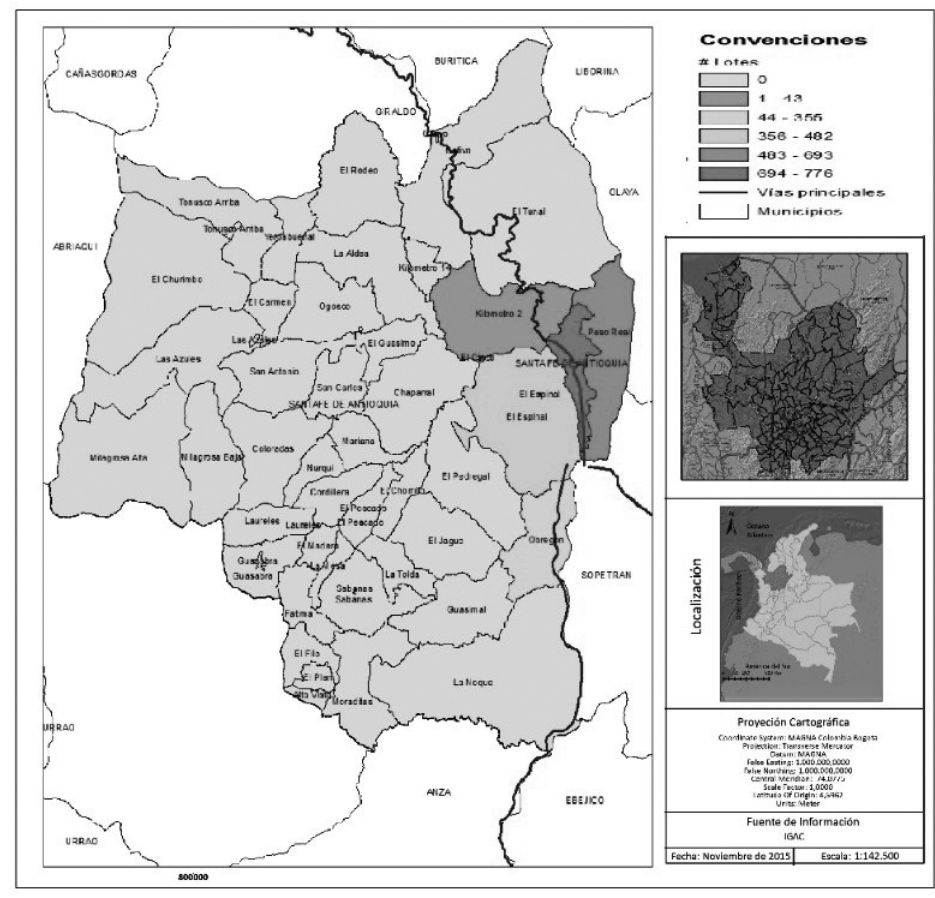

Fuente: Elaboración propia con base en datos de López (2013). 
En este contexto, es posible identificar los procesos de gentrificación y obsolescencia territorial a partir del turismo en diferentes manifestaciones del territorio. Es de anotar que el destino turístico de Santa Fe de Antioquia es producido con base en dos imaginarios que también tienen dos mercados diferenciados. El primero, dirigido al mercado nacional e internacional, es el de pueblo colonial, con características religiosas, culturales y arquitectónicas particulares. Este mercado se caracteriza porque es de mayores ingresos y esto tiene relación con las tarifas de los servicios que ofrecen los hoteles ubicados en el centro histórico o sus alrededores. Según información recolectada en el trabajo de campo, las tarifas en estos hoteles, un fin de semana de temporada baja, en una habitación con aire acondicionado y con algún tipo de alimentación está en un promedio de \$240.000 COP, lo que equivale a un $36 \%$ de un salario mínimo mensual en Colombia para el 2016. Esto quiere decir que las clases bajas que reciben este salario no son las que acceden a este tipo de servicio.

El segundo imaginario que correspondería a un nivel regional, por su parte, quiere fortalecer la idea de un destino de veraneo y el atractivo histórico pareciera ser simplemente un acompañamiento. Así, las inmobiliarias y hoteles son los que se encargan de potenciar este imaginario regional. Slogan como: "Su apartasol en Santa Fe de Antioquia”, “¡Casas Campestres en lotes independientes! Uuuy... ¡Esto sí es un verdadero descanso!", muestran cómo se intenta potenciar el imaginario de veraneo en Santa Fe.

Estas inmobiliarias también tienen un enfoque hacia personas de altos ingresos, ya que, por ejemplo, uno de los conjuntos que se promocionan actualmente, tiene un valor de $\$ 400.000 .000$ COP aproximadamente; siendo casas que solo se utilizan los fines de semana o en vacaciones, entonces, mostraría el tipo de familias a las que está dirigida. Los días de sol son la alternativa que se le ha dado a las personas de menores ingresos para disfrutar de este imaginario; 
en promedio su precio es de $\$ 50.000$ COP, e incluye el uso de las zonas húmedas de los hoteles y almuerzo, pero no alojamiento.

La existencia de estos dos imaginarios turísticos en el municipio lleva a que se quiera transformar el territorio, de tal forma que corresponda a las imágenes e imaginarios que se construyen. El imaginario histórico quiere que permanezca el territorio, ya que esa es su esencia, lo que lleva a que barrios cercanos que no tengan estas características se tiendan a ocultar. El puente de occidente, que es uno de los atractivos más importantes, al estar alejado del centro histórico, requiere una ruta que comunique los dos puntos (Ver Figura 4) y ahí se genera una disyuntiva para los actores de este imaginario, pues se trata de dos pequeñas islas que se deben relacionar y dejar de lado todo aquello que se debe transitar para llegar al puente.

El segundo imaginario, el de veraneo, también trata de generar "islas" en el territorio, las cuales permitan que el turista disfrute de este imaginario (Ver Figura 4). De esta manera, se han comenzado a construir una gran cantidad de urbanizaciones y ciudadelas que durante los fines de semana están ocupadas, mientras en semana no hay ningún tipo de habitante. Como se observa en la Figura 5, este tipo de construcciones fragmenta el paisaje tradicional. 
Figura 4. Ubicación atractivos turísticos y barrios de Santa Fe de Antioquia.

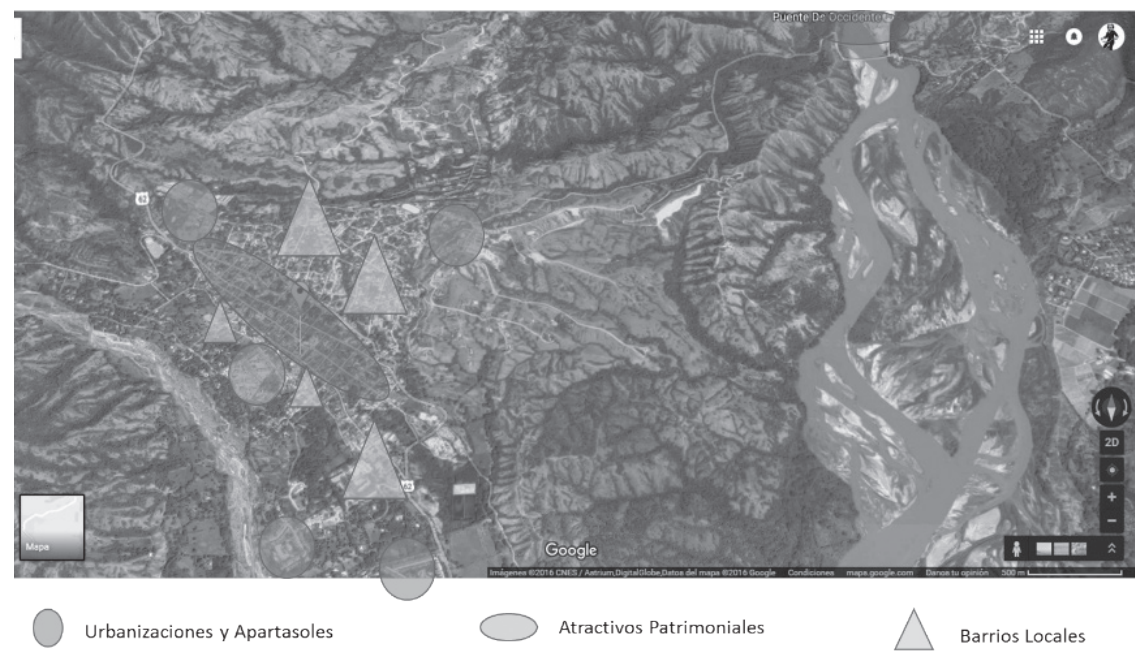

Fuente: Elaboración propia con base en mapa de Google Maps.

Figura 5. Paisaje fragmentado por ubicación de urbanización en Santa Fe de Antioquia.

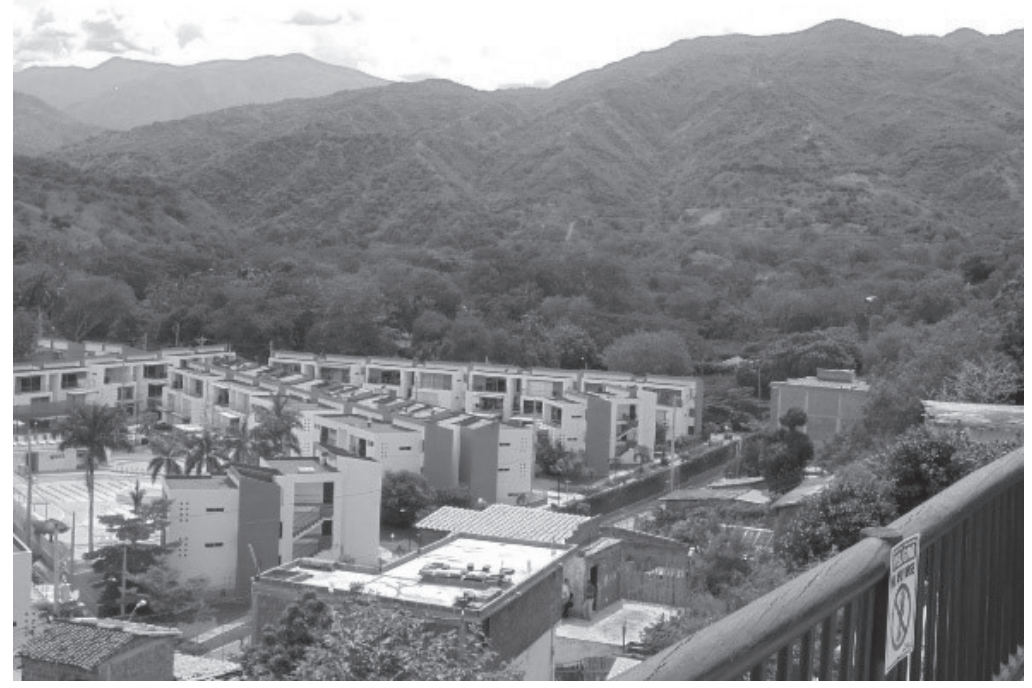

Fuente: Propia de trabajo de campo julio de 2016. 
En esta medida, la suma de estos dos imaginarios nos entrega como resultado un territorio que viene siendo transformado con el fin de fortalecer su papel turístico a nivel regional, nacional e internacional. Esta finalidad se da a partir de diferentes actores, la mayoría de los cuales están por fuera del territorio, ya que localmente se han interesado en los últimos años por fortalecer únicamente la vocación turística patrimonial y dejar a un lado su carácter de veraneo.

Las acciones para plasmar en la realidad, lo que se ha construido desde las imágenes y los imaginarios son los que han venido provocando la gentrificación y obsolescencia en Santa Fe de Antioquia. La construcción de urbanizaciones, hosterías, fincas, etc., que son cerradas y vienen a constituir "quistes territoriales" (Salva, 1998), componen un aspecto gentrificador del turismo en Santa Fe de Antioquia. Estos espacios han aumentado el precio del suelo, desplazando las actividades económicas que se desarrollaban allí y una fragmentación espacial que no les permite a los actores locales utilizar libremente esos espacios.

Así, el enfrentamiento de estos dos imaginarios y sus acciones hacen que el territorio evidencie de una manera más fuerte los fenómenos de la gentrificación y obsolescencia territorial. En la Figura 6 , se observa un resumen de estos fenómenos y su localización en el espacio. En color naranja se identifican los lugares donde se han construido las urbanizaciones y ciudadelas más importantes del municipio, las cuales se localizan cerca al centro histórico. Estos espacios son considerados como una muestra de la gentrificación turística que experimenta el municipio, esto ha sido resultado del análisis de la información de campo y coincide con estudios similares (Londoño, 2016). En color rojo se presenta la obsolescencia turística, esta se muestra básicamente alrededor del centro histórico, zonas de frecuente movilidad turística y cercanas a urbanizaciones. 
Figura 6. Localización de lugares con gentrificación u obsolescencia en Santa Fe de Antioquia ${ }^{9}$.

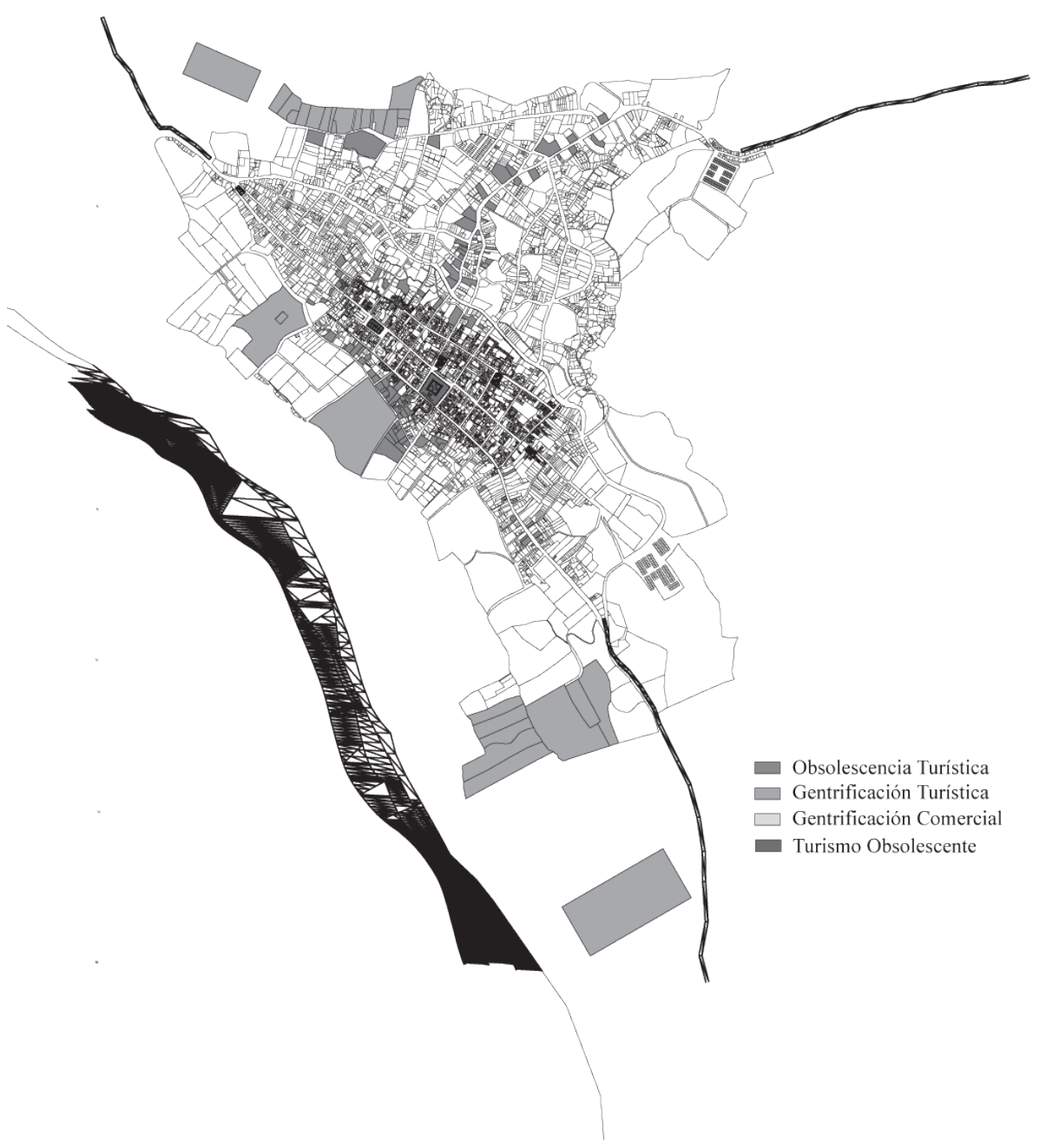

Fuente: Elaboración propia con base en información entregada por la Secretaría de Planeación Municipal de Santa Fe de Antioquia.

9 Estos lugares fueron identificados a partir de los cambios que se han observado allí y según el fenómeno en el cual se pudieran clasificar. Para su selección se tomó en cuenta visitas previas, algunos diálogos con actores locales y cambios observados en los mapas. 
El primer caso tiene que ver con el imaginario patrimonial, ya que estos barrios han tendido a dejar de lado las características arquitectónicas del centro, lo que perjudica la imagen de un municipio que se visita para reactivar la memoria y sentirse como en un espacio de otros tiempos. El segundo tiene que ver con ambos imaginarios. Una de las mayores movilidades de turistas en el municipio se presenta entre el centro histórico y el puente de occidente, por lo que en el recorrido se quiere conservar cierta armonía patrimonial. La otra movilidad se relaciona con la llegada de los turistas desde Medellín hacia las ciudadelas; para lograr esto, se deben atravesar algunos barrios que no hacen parte del centro histórico, y también va en contra de la imagen de descanso dentro de un pueblo patrimonial que ofrecen las inmobiliarias y los hoteles principalmente.

En cuanto a la cercanía de las ciudadelas y urbanizaciones, la obsolescencia de esos barrios responde a la necesidad de mostrar una imagen moderna y cosmopolita durante el periodo de recreación al interior de dichas edificaciones. Estos barrios no cuentan con un estilo arquitectónico colonial o republicano, ya que en algunos casos son de construcción reciente; por tanto, no aportan a la sensación que se quiere crear en el turista. La existencia de esta idea de obsolescencia se puede observar claramente en la proliferación de barreras a la vista hacia el interior o exterior de la ciudadela. Tales barreras permiten potenciar la imagen arquitectónica moderna interna y hacer ver como obsoletos aquellos barrios que los rodean.

De otro lado, con color morado se identificaron los espacios que ya se muestran como un reflejo de un turismo obsolescente. Las intervenciones en ambos espacios (parque de la Chinca y parque principal), le da sustento a la denominación que aquí hacemos. En el parque de la Chinca se hizo una intervención de carácter social, a través de la interrelación de hoteleros, población local, comerciantes y alcaldía municipal. Entre todos se reapropiaron del parque y están 
eliminando las prácticas de prostitución, fiestas hasta altas horas de la noche, entre otras, las cuales fomentaban la presencia turística allí. Ahora es en el único lugar del municipio en que se observan mensajes directos, hacia el turista, de respeto por el patrimonio y la paz de los habitantes (Ver Figura 7).

Figura 7. Intervención de los actores sociales en el Parque de la Chinca.
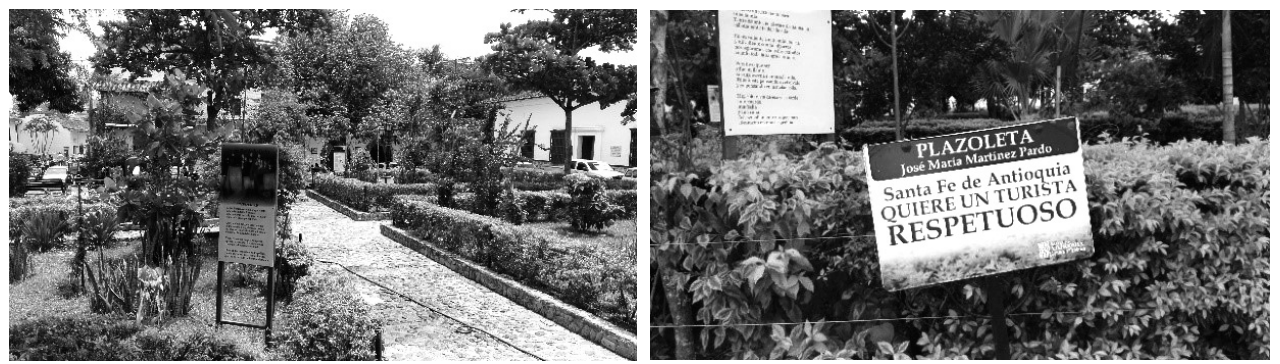

Fuente: Fotografías Propias, julio 29 de 2016.

En el parque principal se adelanta una intervención de carácter institucional. Se está remodelando completamente, ya que diferentes actores han coincidido en que la presencia desmedida de comerciantes y turistas ha logrado un deterioro patrimonial. Los principales preocupados por la situación del parque fueron los actores locales y, por ello, desde el anterior gobierno local se inició un proceso de remodelación. Sin embargo, y este es el punto que da pie a entender este espacio como un reflejo de un turismo obsolescente, la comunidad estuvo totalmente en contra de esa intervención. Tal intervención en el espacio buscaba consolidar el imaginario de veraneo en el municipio, a tal punto de proponer la localización de objetos propios para momentos de ocio en piscinas (como sillas para tomar el sol) en el parque principal.

La comunidad fue tajante al decir que el problema no era el diseño y el estilo del parque, el problema era el uso que se le había dado y que era necesario recuperarlo, pero no cambiar su esencia patrimonial. 
Esto es un indicador de un significado generalizado de un turismo obsolescente en el parque y no de un deterioro u obsolescencia generalizada del mismo. En la Figura 8 se muestra un comparativo entre el parque antes de la intervención y durante esta intervención, ya que, en más de una ocasión, durante reuniones en el municipio, se escuchaba el comentario que con el sólo hecho de haber retirado los vendedores y turistas, ya el parque estaba tomando forma nuevamente.

Figura 8. Comparación antes y después de la remodelación del parque principal Santa Fe de Antioquia.
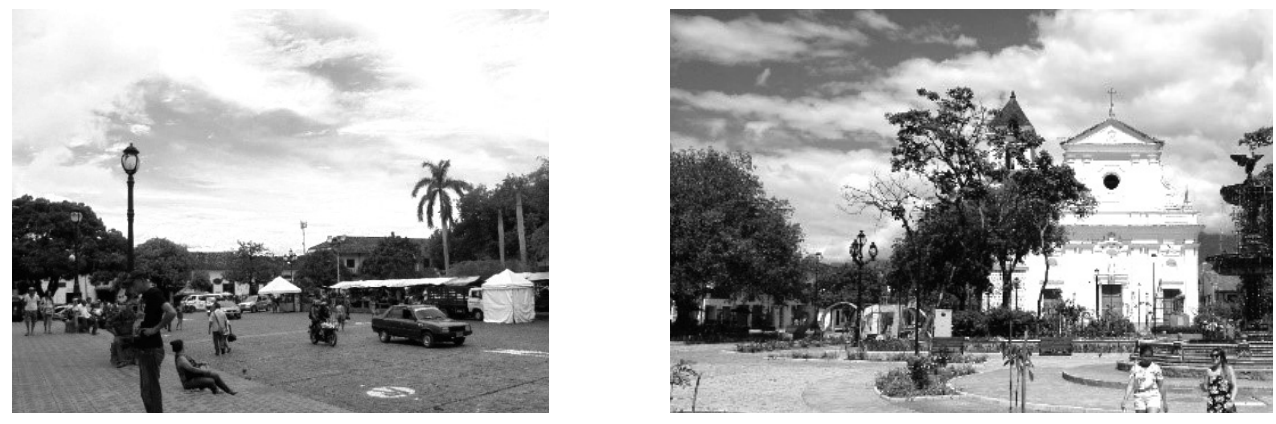

Fuente: Fotografías propias, trabajo de campo 2016 - 2018.

El otro color representado en la Figura 6 es el amarillo que corresponde a la gentrificación comercial. Se trata de lugares que han sufrido cambios en su uso para fomentar un comercio en pro del turismo. Directamente desplazando un comercio local, pero indirectamente fomentando prácticas que incentivan desplazamientos posteriores de residentes, e incrementando sentimientos de baja pertenencia a estos servicios que tienden a ser más globales. Aquí se caracteriza la localización de nuevas entidades financieras, nuevas discotecas, restaurantes de comida internacional y establecimientos de grandes superficies. Se han localizado en el centro histórico o cerca a otros espacios de gentrificación turística para aprovechar la presencia de sus consumidores predilectos: los turistas. 


\section{Conclusiones}

La gentrificación y la obsolescencia territorial son fenómenos nuevos que se están observando en la actualidad; están relacionados con el crecimiento urbano y la posibilidad de satisfacer la necesidad estética de los individuos. En la teoría clásica de la gentrificación se suele ver que el proceso inicia con un espacio que se ha visto deteriorado por desuso, abandono o, incluso, el direccionamiento de algún actor social en particular. En esta medida, si hacemos una similitud de deterioro con el fenómeno de la obsolescencia, parece ser natural que la obsolescencia sea un paso previo para la gentrificación de un espacio.

No obstante, lo que analizamos en este capítulo es que tal relación no tiene por qué siempre ser así. En este caso, se mostró que el turismo es capaz de producir ambos fenómenos simultáneamente, en la medida en que muestra unos espacios, pero al mismo tiempo oculta otros, en pro de la imagen que se haya vendido del destino. Las consecuencias de tener al mismo tiempo estos fenómenos en un territorio son nefastas, tienden a concentrarlo en favor de unos intereses económicos, así como a generar fragmentaciones internas, tanto sociales como materiales.

Para el caso de Santa Fe de Antioquia, se mostró la presencia simultánea de estos fenómenos. Como resultado: este es un municipio con condiciones socioeconómicas relativamente bajas, pero lo más preocupante es que muchos actores locales están inmersos en el discurso turístico del desarrollo. Es decir, el turismo, por lo general, se muestra a sí mismo como una fuente inagotable de desarrollo para los territorios, haciendo que los actores sociales no vayan en su contra, porque sería rechazar el progreso de su territorio. En esta medida, dado que el turismo es el que está provocando ambos fenómenos en el municipio, pero al mismo tiempo se le ve como la solución para 
sus problemas de desarrollo, esto hace que no se puedan resolver fácilmente las manifestaciones de esos fenómenos. Sólo cuando haya una apropiación real desde los actores locales sobre el turismo se va a lograr solucionar esta situación.

\section{Referencias}

Cámara de Comercio de Medellín. (2015). Estructura Empresarial por Centro Regional, Municipio y Tamaño de Empresa. Recuperado de http:// www. camaramedellin.com.co/ site/ ServiciosEmpresariales/ Informacion- Empresarial/ EstadisticasCamara.aspx

Cámara de Comercio de Medellín. (2016). Estructura Empresarial 2016. Recuperado de http://www.camaramedellin.com.co/ site/Servicios-Empresariales/Informacion-Empresarial/ Estadisticas-Camara.aspx

Cócola, A. (2015). Tourism and commercial gentrification. The Ideal City: Between Myth and Reality. Representations, Policies, Contradictions and Challenges for Tomorrow's Urban Life. Conferencia llevada a cabo en el RC21 International Conference. Recuperado de http://www.rc21.org/en/wpcontent/uploads/2014/12/E4-Cócola-Gant.pdf

Foucault, M. (1984). Cómo se ejerce el poder. Recuperado de http://www.unizar.es/deproyecto/programas/docusocjur/ FoucaultPoder.pdf

Gobernación de Antioquia y Departamento Administrativo de Planeación. (2017). Anuario Estadístico de Antioquia 2017. Colombia: Gobernación de Antioquia. Recuperado de http:// www.antioquiadatos.gov.co/index.php/anuario-estadistico-deantioquia-2017 
Haesbaert, R. (2013). Del mito de la desterritorialización a la multiterritorialidad. Cultura y Representaciones Sociales, 8(15), 9-42. Recuperado de http://www.scielo.org.mx/scielo. php?script=sci_arttext\&pid=S2007-81102013000200001\&ln $\mathrm{g}=\mathrm{es} \& \mathrm{nrm}=\mathrm{iso}$

Hiernaux, D., y González, I. (2014a). Gentrificación, simbólica y poder en los centros históricos. Scripta Nova, 493(12), 1-15.

Hiernaux, D., y González, I. (2014b). Turismo y gentrificación: pistas teóricas sobre una articulación. Revista de Geografía Norte Grande, 58, 55-70.

Instituto de Estudios Regionales. (2007). Occidente Desarrollo Regional: una tarea común universidad-región. Medellín, Colombia: Universidad de Antioquia.

Kesar, O., Dezeljin, R., y Bienenfeld, M. (2015). Tourism gentrification in the city of Zagreb: time for a debate?. Interdisciplinary Management Research, 11, 657-668.

Londoño, J. (2016). La declaratoria del centro histórico y el marketing turístico como indicadores de la gentrificación en Santa Fe de Antioquia, una lectura desde el paisaje artificio. Iconofacto, 12(19), 43-64.

López, L. (2013). Impactos territoriales del turismo y lineamiento de ordenación para territorios con vocación turística. Estudio de caso en el municipio de Santa Fe de Antioquia - Colombia. Recuperado de https://papers.ssrn.com/sol3/papers. cfm?abstract_id $=2561543$

Massey, D. (1993). Power-geometry and a progressive sense of place. En J. Bird, B. Curtis, T. Putnam, \& L. Tickner. (Eds.), Mapping the futures: local cultures, global change (59-69). London, England: Routledge. 
Muñoz, E. (2017). Territorio de postal: la dualidad del turismo en Santa Fe de Antioquia (Colombia). Cuadernos de Geografía: Revista Colombiana de Geografía, 26(2), 153-174. Recuperado de https://doi.org/10.15446/rcdg.v26n2.59237

Nates, B. (2008). Procesos de gentrificación en lugares rururbanos: presupuestos conceptuales para su estudio en Colombia. Revista de Antropología y Sociología. Virajes, 10, 253-269.

Ossa, B., y Rippes, M. (2014). Gentrificación y boutiquización en la calle Almirante Montt de Valparaíso: transformaciones y relaciones socio-espaciales. Revista Planeo, 19, 1-19.

Raffestin, C. (2011). Por una Geografía del Poder. México: Colegio de Michoacan.

Salva, P. (1998). Los modelos de desarrollo turístico en el mediterráneo. Cuadernos de Turismo, 2, 7-24.

Smith, N. (1996). The new urban frontier. Gentrification and the revanchist city. London and New York: Routledge.

Universidad Nacional de Colombia. (2006). Plan Director para la Ordenación Territorial del Área de Influencia de la Conexión Vial valle de Aburrá-Río Cauca en la Región del Occidente Antioqueño: Como efecto de la habilitación del Túnel de Occidente. Medellín, Colombia: Universidad Nacional de Colombia, Gobernación de Antioquia.

Vera, J., López Palomeque, F., Marchera, M., y Antón Clavé, S. (2013). Análisis territorial del turismo y planificación de destinos turísticos. Tirant Humanidades. 
